\title{
Teacher Scaffolding: An Exploration of Exemplary Practice
}

\author{
Jennifer Masters and Nicola Yelland
}

Faculty of Education, Queensland University of Technology, Brisbane, Australia j.masters@qut.edu.au

Keywords: classroom teaching/practice, integration of ICT, primary education

\begin{abstract}
While computers have increasingly been used in classroom over the last twenty years, their application has often been mundane; being merely used to reinforce existing educational practices rather than as a catalyst for educational innovation. An effective way to bring about change may be to identify instances of best practice and then study associated strategies that may be useful for teachers trying to use computers in new and meaningful ways. This study investigates strategies used by a teacher deemed to be exemplary at using computers and associated technology in her classroom. It involved observing and recording teaching sessions conducted by the teacher. This paper discusses the learning task, the children's progression through the task and the teaching strategies used. In particular, it looks for instances of teacher scaffolding as a strategy for supporting children working with computers.
\end{abstract}

\section{BACKGROUND}

One of the most significant directions evident in education in recent times has been the restructuring of education catalysed by technological innovation. An integral and core part of the restructuring process is a change to instructional practices. New models for teaching and learning incorporate a focus on problem-solving, collaborative learning, real purpose tasks and transformed teacher roles (e.g. Jonassen 1996). As teachers are expected to adopt new models, they also need to reassess their approach towards educational processes and the integration of technology tools (Bork 2000). It 
seemed that the advent of technology-based school reform demanded new attitudes from teachers, different strategies and even that teachers adopt a new teaching paradigm.

Even though policy was requiring a new approach to teaching with computers, research indicated that resistance to change was still an impediment. While transformation in practice was demanded, it seems that teachers were finding it difficult to make the adjustments required. Sandholtz, Ringstaff and Dwyer (1997) suggested that rather than blame teachers for their reluctance to use technology in new ways, the problem should considered from the teachers' perspectives. Teachers have a responsibility to foster learning for their students and they need to be reassured that using computers in constructive ways will promote positive learning outcomes. Research from the Apple Classroom of Tomorrow (ACOT) project (Sandholtz et al. 1997) found that although teachers initially relied on traditional teaching strategies when using computers, over time, with supportive teacher development, they did adapt to more constructivist approaches.

Campoy (1993) suggested that the use of computers and especially software that promotes constructivist learning might actually be a catalyst to encouraging teachers to teach in more constructivist ways. This was supported by Hannafin and Savenye (1993) who felt that the show-casing of success stories of teachers using computers in meaningful ways would encourage others to try new methods. Additionally, in a report on the use of technology (President's Committee of Advisors on Science and Technology 1997) it was identified that teachers need to be provided with pedagogical support, including opportunities to observe within the classrooms of successful technology-using teachers.

A major component in the attempt to bring about effective computer use in schools is the type of activity that teachers are initiating in their classrooms. Research over the last twenty years has shown that using computers for traditional educational tasks, in traditional teaching styles has not significantly changed educational outcomes (Jones, Valdez and Nowakowski 1995). Instead, effective computer implementation is hinged on new learning tasks that promote "engaged, meaningful learning and collaboration involving challenging and real-life tasks, with technology as a tool for learning, communication and collaboration" (p. 1). Therefore, when examining teaching practices, we must also be cognisant of the type of activity that the children are engaged with. In particular we need to seek 'rich tasks', i.e. tasks that are designed to engage children with "knowledges, fields and paradigms that have power and salience in researching, analysing and interpreting the world" (Education Queensland 2000). 
In previous research (Yelland and Masters 1999) we have identified that teacher scaffolding is a key aspect of effective computer use by children. The term 'scaffolding' was first described by Wood, Bruner and Ross (1976), who defined it as "a process that enables a child or novice to solve a problem, carry out a task or achieve a goal which would be beyond his unassisted efforts (p. 90)". The concept arose out of a consideration of Vygotsky's theories in which he hypothesised that guided interactions with an adult or a more capable peer could assist children to develop at a higher level of operation. Vygotsky suggested that this support allowed a child to extend through the Zone of Proximal Development. Consequently, when scaffolding is provided, a child may not only accomplish the task at a higher level but also internalise the thinking, strategy or mechanisms used to be able to approach similar tasks. (Rogoff 1990).

Research has shown that although the nature of the scaffolding is dynamic and must be modified according to the task and the learner, several key characteristics of scaffolding can be identified (Beeds, Hawkins and Roller 1991). First, the interaction must be collaborative, with the learner's own intentions being the aim of the process (Searle 1984). Second, the scaffolding must operate within the learner's zone of proximal development. Rather than simply ensuring the task is completed, the scaffolder must access the learner's level of comprehension and then work at a slightly beyond that level, drawing the learning into new areas of exploration (Rogoff 1990). The third characteristic of scaffolding is that the scaffold is gradually withdrawn, as the learner becomes more competent. Palincsar (1986) suggests that this notion re-inforces the metaphor of a scaffold as used when constructing buildings in that the means of support is both adjustable and temporary.

In our own research (Yelland and Masters 1999) we have identified that scaffolding with computers can also be classified into categories. In addition to cognitive scaffolding where a teacher can support children when constructing understanding, we also found that scaffolding may be affective, with the teacher supporting the children emotionally, and strategic, in which the teacher can provide task management support. A final category that is especially pertinent to using computers and associated technology is technical scaffolding. In this situation the teacher facilitates the operation of both the hardware and the software, in order for the students to focus on the learning aspects involved. 


\section{THE SETTING}

The classroom chosen for this investigation was somewhat special. The research school was designed to be a state-of-the-art technology institution and was purpose built with facilities to support the integration of information and communication technologies in the classrooms. The infrastructure of the school incorporated at least four networked multimedia computers in each classroom with ceiling wiring to enable them to be situated in central hubs. Each double classroom also had a large screen monitor on a movable trolley that could be connected to any of the computers. Additionally, the students had access to peripherals such as still and movie digital cameras and scanners. A full time technology co-ordinator supports classroom teachers at the school.

Woodcrest College opened in 1998 as a primary campus and in 2000 extended its scope to incorporate a P-12 curriculum over a lead-in period, which will reach capacity in 2004. Another feature of the school is the Teacher Development Centre, which provides professional development for teachers in effectively using technology in classroom teaching practice. The centre runs a program in which teachers from other schools can visit to observe the teachers using technology with students and to participate in discussions about staff development, and school change. The stated learning outcomes of the project are that participants are presented opportunities to develop an understanding of:

- Constructivist classroom practice

- The role of educational technology in supporting effective learning and teaching

- Strategies to integrate educational technology into classroom practice

- A range of applications of educational technology to support a student centred constructivist approach to learning and teaching.

The class we observed in this study was a double year two/three group, with 52 children aged between 6 and 9 years. The group occupied two large adjoining rooms, separated by a sliding panel that could be closed or opened as required. The setting had been arranged so one room served as an activity area with very little furniture, while the other was used for seated activities, with tables for groups of children. There were eight computers located in pairs across both rooms, with four moveable workstations in the activity area to allow for maximum adaptability.

There were two teachers with the class who had both been teaching at the school since it was opened ( 3 years). One teacher, Angela was a graduate when appointed, while the other, Gillian, had previous teaching experience and was completing a Masters degree specialising in computers in education. Both teachers were recognised as having expertise with integrating 
computers into classroom activity and both regularly hosted visitors from the teacher development program.

\section{THE ACTIVITY}

The class had been investigating 'mini-beasts'. This topic had been integrated across the curriculum and the children had been examining the lifestyle and habits of various mini animals such as insects, arachnids and small reptiles, e.g. geckos. The culminating activity for the theme was for the children to work in groups of five or six and use the computer to produce a modelling clay animation (a quick-time movie) depicting a sequence in the life of a chosen mini-beast. In the animation they needed to illustrate the mini-beast's home, the food source and its mechanism for movement. In order to conceptualise their animation, the children had examined a 'Wallace and Grommit' movie, a popular children's series that uses a modelling clay technique to produce animation.

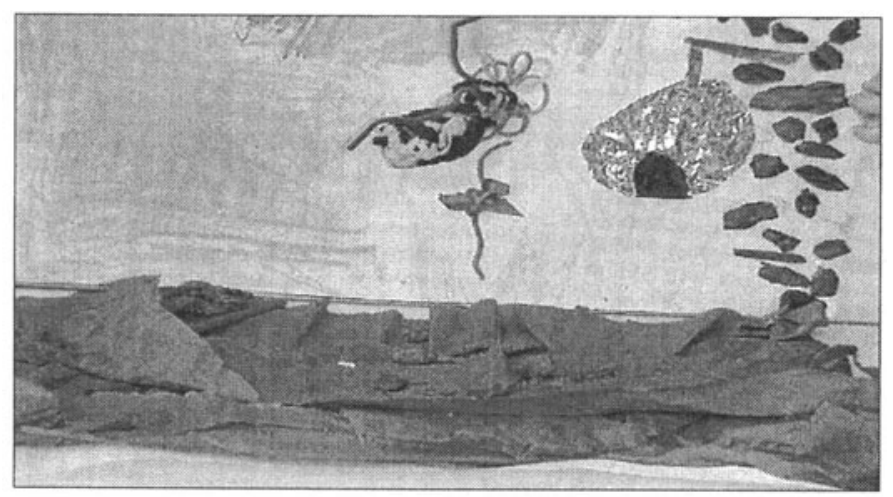

Figure 1. Bee set with bee, hive and flower

The activity was broken down into a number of tasks:

- Decide on the mini-beast and define the home, food and movement for that beast.

- Use a storyboard to plan the sequence. The sequence should include at least six stages.

- Design and produce the props. Produce a mini-beast using modelling clay and develop the set for the movie. This will include a backdrop, a foreground and any objects on the set.

- Film the sequence. Assemble the set and set up the digital camera on a tripod. Take a series of still shots of the mini-beast on the set in order to develop the animation. 
- Take the disk/s with the still shots to a computer and load them into the quick-time software.

- Create a movie. Edit the still shots to make the animation sequence. This includes sequencing the shots and removing any unwanted files. An option may be to add a music sound track.

- Share your movie with the class and reflect on the processes you used and the decisions you made.

\section{RESEARCH FOCUS}

While this activity provides a number of opportunities for research, particularly in relation to 'rich tasks', the focus that we had during this study related to the ways in which the teacher scaffolded the children during the task, and particularly while using the technology in steps four to seven. The task was one of several on-going projects happening in the classroom during the week of our visit. During this time, both teachers worked with all groups within the class on a needs basis. In order to isolate the task in the milieu of classroom practice, we video-recorded the progress of two groups through the 'mini-beast movie' production over several consecutive days. In these sessions, the more experienced teacher, Gillian, supported the 'bee' group and the 'spider' group in their work with the technology.

\section{PROCEDURE}

Before the children began any work with technology, the technical processes of the task were explained to the class during a mat session in the activity room. The large monitor was used for this session and both teachers and all the children were present. While the children had had previous experience with both the digital camera and the editing software, Gillian explained and demonstrated each step of the process in the context of the new task. In this situation, the other teacher, Angela, adopted a secondary role which involved asking guiding questions and reinforcing the processes described by Gillian. After this briefing, the groups were allowed to move to the technical aspects of the task when they were ready for stage 4 or if it was their turn. It should be noted too, that this procedure was reinforced in a debriefing session at the end of activities for the day. In a half-hour mat session, the groups were asked to briefly share their progress for the day, any problems they encountered and any strategies that they used to solve those problems. This meant that children who had not yet attempted the animation task could benefit from the experiences and advice of others. 
When the children in the groups worked on the production, it seemed they had plenty of previous experience with working with technology in this mode. In general the children appeared to be confident with the equipment (digital camera and editing software) and also the animation process. They also managed turn taking and assignment of roles within the task, although this was one of the aspects that needing scaffolding from Gillian (especially with the bee group). During this time Gillian remained within range of the students, in order to help or contribute when necessary.

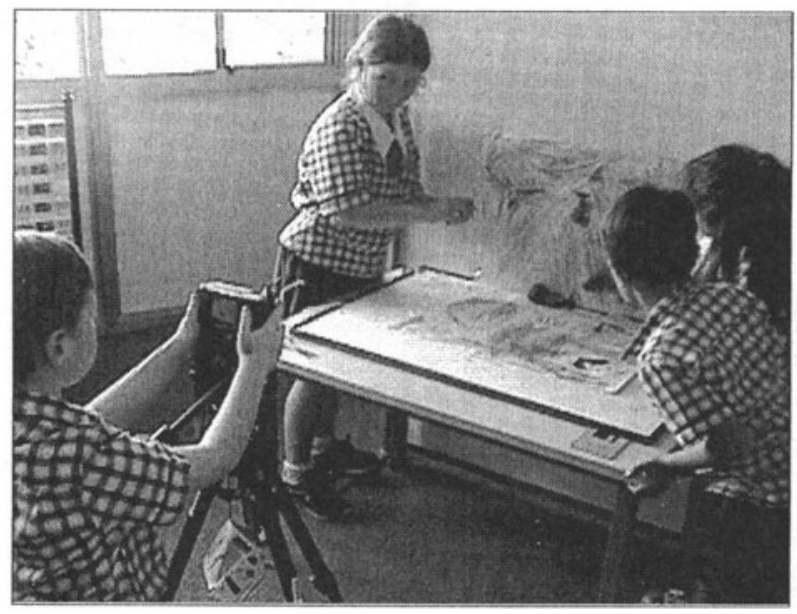

Figure 2. The animation process

The reflection stage consisted of a mat session with the large monitor for display. Each group nominated a spokesperson and another person to operate the computer. The presentation was not rehearsed, rather Gillian choreographed the process through directed questioning. The structure tended to be a brief introduction on the content, a presentation of the product and then a reflection on decisions and problem solving that occurred during the process. During the presentation the class members were prompted to ask questions and the spokesperson was encouraged to call on members of the team in order to respond thoroughly.

\section{SCAFFOLDING STRATEGIES}

On first impressions it seemed that Gillian had a passive role and during much of the activity monitored without comment, sometimes from the other side of the room. However when reviewing the process, it was obvious that 
she was actually providing scaffolding throughout the whole task. During the production of resource she implemented a number of scaffolding strategies that can be summarised as:

\subsection{Cognitive strategies}

Gillian systematically monitored the concept development in the group activity. This incorporated steering the children through decision making to reach their goal product. This included:

- Task reinforcement - "Now, what is it exactly that you need to do?"

- Seeding ideas during group discussions - In response to a spinning bee problem -"What about if you use two pieces of thread instead of one to suspend your bee?"

- Reviewing progress - "OK, where are we up to? What is next?"

- Conceptualisation reinforcement - "So where does the bee have to go next?"

- Narrowing choices - "Well you could make the spider eat the fly now or you could wait until it gets back to the web. What do you think?"

\subsection{Strategic}

Group management was a key factor during the task, especially as a group of six children was fairly large. Gillian supported the group dynamic, when necessary, by:

- Defining roles - "Now, you need two people holding the spider and the camera person needs to be here"

- Recruiting - "Sam, why don't you come and have a go at taking a picture?"

- Time management - "We have about 5 minutes left. What are the tasks left to do?"

\subsection{Affective}

The groups that were engaged in the task during our observations were remarkably confident and supportive of each other. It is likely that for this reason we saw little in terms of affective scaffolding. The affective scaffolding that we observed included:

- Granting permission - "Can we turn the bee so the camera is looking at this side?" - "Yes of course you can, that will be great."

- Reassurance - "You're going really well. Just a few more shots and you will be finished." 


\subsection{Technical}

In terms of technical competence, the children obviously had experience using computers and were not afraid to try new options. It is probable too that the prior instruction session prepared the children effectively for their technical tasks. The technical scaffolding that we observed included.

- Technical instruction - When the children were taking pictures - "You need to squeeze the button slowly and keep pressing until it goes click. It is different to a normal camera".

- Technical recovery - If the children did make a technical mistake or something went wrong with the equipment, Gillian increased the amount of intervention considerably. This may have incorporated prompts or guiding questions - "Lets look through the menu and see if we can find an option that will help" or even physical intervention - "Hang on, I'll just get that back for you".

\section{DISCUSSION}

The support that Gillian provided for the children is perhaps typical teacher activity in any primary classroom. However by analysing this activity we can begin to tease out strategies that can be suggested to other teachers for computer implementation in their classrooms. In particular we would like to identify whether this activity can be considered as scaffolding, in which the interaction is collaborative, with the learners' intentions as a focus, where the learners are crossing their own zones of proximal development and the scaffolding is being progressively withdrawn. While the aspect of a teacher scaffolding a group of children simultaneously is somewhat complex, there is evidence to suggest that Gillian was scaffolding during the task.

The first aspect is to establish whether Gillian worked in a collaborative mode with the children, with their intentions as the goal. The fact that the children were working in a group meant that individuals needed to negotiate in terms of their own intentions. However, the nature of the task did ensure that the goal was actually determined by the students. In this sense, the teacher's intentions (that is, the objectives of the task) 'faded' to groups intentions in that teacher direction did not dominate and the children had a great deal of control.

Possibly the most difficult aspect of scaffolding to conceptualise is the notion of crossing the Zone of Proximal Development. Even with an individual child in a one to one scaffolding situation, it could be difficult to ascertain understanding levels and consequential shifts. The concept of 
promoting equivalent learning with six children at once is quite unrealistic. This inequity in achievement was especially apparent with the bee group, which had several group members off-task and uninvolved, while two members dominated the activity. Nevertheless, it was also evident that with both groups, some participants seemed to be gaining key concepts and making significant shifts in understanding. This observation was reinforced when the children were able to reflect on their processes and achievements.

Given the small window of time in which we observed the class, it would be inappropriate to make sweeping claims about Gillian applying scaffolding and then withdrawing the scaffolds as the children adopted new concepts. However, an interesting observation was that Gillian implemented quite different amounts of scaffolding for the two groups. While both groups we given the opportunity to experiment with both the technology and the task, Gillian used far less intervention with the spider group. It is possible that the spider group was at a different stage of development to the bee group and that some early scaffolding had already been withdrawn. Our initial observation that Gillian had a relatively passive role in the group work may also contribute to this theory. It is likely that much of the scaffolding that supported the children when they initially started using the digital camera and the computer had been withdrawn as the children became more comfortable with its use.

\section{CONCLUSION}

This exploratory investigation of strategies used by an experienced teacher has provided some interesting insights into how a teacher might scaffold when children are using technology. We have found that an experienced teacher constantly monitors children's progress and contributes in a number of different ways during a task. The teacher must also know when to withdraw support in order to allow children to explore and construct new understandings. Further research in this area will investigate the role teacher scaffolding plays in an individual child's learning while using computers. It will also examine a teacher's management of their class activity and especially how a teacher can scaffold each class member while they use computers for learning goals. 


\section{REFERENCES}

Becker, H. J. (1994) How exemplary computer-using teachers differ from other teachers: Implications for realizing the potential of computers in schools. Journal of Research on Computing in Education, 26 (2), pp. 291-321.

Beed, P., Hawkins, M. and Roller, C. (1991) Moving learners towards independence: The power of scaffolded instruction. The Reading Teacher, 44 (9), pp. 648-655.

Bork, A. (2000) Learning technology. EDUCAUSE Review, January/February, 1.

Campoy, R. (1992) The role of technology in the school reform movement. Educational Technology, 32(8), pp. 17-22.

Education Queensland (2000) New Basics Project Technical Paper.

[http://education.qld.gov.au/corporate/newbasics/html/tnbf.html] 4/8/2000.

Hannafin, R. and Savenye, W. (1993) Technology in the classroom: The teacher's new role and resistance to it. Educational Technology, 33(6), pp. 26-31.

Jones, B., Valdez, G., Nowakowski, J. and Rasmussen, C. (1995) New times demand new ways of learning. Plugging In: Choosing and Using Educational Technology, Council for Educational Development \& Research, North Central Regional Education Laboratory, Washington, D.C. [http://www.ncrel.org/sdrs/edtalk/newtimes.htm].

Jonassen, D. (1996) Computers in the classroom: Mindtools for critical thinking. PrenticeHall, Englewood Cliffs, N J.

Palincsar, A. S. (1986) The role of dialogue in providing scaffolded instruction. Educational Psychologist, 21(1 \& 2), pp. 73-98.

President's Committee of Advisors on Science and Technology (1997) Report to the president on the use of technology to strengthen K-12 education in the United States. pp. 1-66. [http://www.whitehouse.gov/WH/EOP/OSTP/NSTC/PCAST/k-12ed.html] 3/2/2000.

Rogoff, B. (1990) Apprenticeship in thinking: Cognitive development in social context. Oxford University Press, New York.

Sandholtz, J., Ringstaff, C. and Dwyer, D. (1996) Teaching with technology: Creating student centred classrooms. Teachers College Press, New York.

Searle, D. (1984) Scaffolding: Who's building whose building? 61(5), pp. 480-483.

Wood, D., Bruner, J. and Ross, G. (1976) The role of tutoring in problem solving. Journal of Child Psychology and Psychiatry, 17, pp. 89-100.

Yelland, N. and Masters, J. (1999) New ways of learning with technology: Scaffolding children learning and understanding. Advanced Research in Computers and Communications in Education: New Abilities for the Networked Society, Proceedings of ICCE'99, IOS Press, Chiba, Japan, pp. 499-506.

\section{BIOGRAPHY}

Jennifer Masters is a lecturer in Technology Education at Queensland University of Technology. She has taught at both Early Childhood and Primary levels and currently specialises in the integration of computing in Early childhood and Primary curriculum. Some specific interest areas include discovery learning and constructivism, using computers for 'real' purposes, publishing and presenting with computers and computer-based problem-solving opportunities - including LOGO. She is currently enrolled 
in a $\mathrm{Ph}$. D course and has research interests relate to young children using computers, with particular focus at present on how teachers can 'scaffold' or support children working with computers. 